\title{
Atenção ao adolescente vítima de violência: participação de gestores municipais de saúde
}

\author{
Assistance for the adolescent victim of violence: \\ participation of local health managers
}

M ariluce Karla Bomfim de Souza ${ }^{1}$

Judith Sena da Silva Santana ${ }^{2}$

${ }^{1}$ Centro de Ciências da Saúde, Universidade Federal do Recôncavo da Bahia. RuaCajueiro s/n, Cajueiro. 44570-000 Santo Antônio deJesus BA. marilucejbv@yahoo.com.br

${ }^{2} \mathrm{~N}$ úcleo Interdisciplinar de Estudo sobre Violência e

Saúde, Universidade Estadual deFeira de Santana.
Abstract This qualitative study ai med at analyzing the participation of the local health managers in the assistance provided to the adolescent victim of violence in the city of Itabuna, Bahia, Brazil. Specific objectives of this study were: to identify how the local health managers perceive violence and its re percussions in adolescence; to identify the public healthcare policies directed to the adolescent implanted by the health system of I tabuna-BA, focusing on violence and on the actions developed by the local health managers toward an effective implantation of these policies. The data collected from interviews and documents were analyzed using the technique of content analysis. A nalytical categories: $\mathrm{Vi}$ olence as any form of physical, moral, psychical or social aggression, omission and disrespect to the human rights; Violence has psychological repercussions in adolescence, causes pain and suffering, compromises the life and the future and generates violence; Assistance for the adolescent victim of violence: limitations and advances of a policy in construction. The results show that the managers have put forth efforts for the effective implementation of the Adolescent $\mathrm{H}$ ealth Program, with the intention to include violence as a focal issue of their actions.

Key words Violence, Adolescent
Resumo Estudo qualitativo quetem como objetivo geral analisar a participação dos gestores municipais de saúde na atenção ao adolescente, vítima de violência, no município de Itabuna, Bahia. São objetivos específicos: identificar percepções dos gestores munici pais de saúde acerca da violência esuas repercussões na adolescência; identificar as políticas públicas de atenção ao adol escente implantadas no sistema municipal de saúde de Itabuna, Bahia, focalizando a violência e descrever as ações desenvolvidas pelos gestores municipais de saúde para a conformação e efetivação das políticas de atenção ao adolescente vítima de violência. U tilizamos como técnica de coleta de dados a entrevista e a análise documental. 0 s dados foram analisados com base na técnica de análise de conteúdo. I dentificamos três categorias analíticas: a violência enquanto qualquer forma de agressão física, moral, psíquica, social, omissão e desrespeito aos direitos humanos; a violência que repercutepsicologicamente na adolescência causa dor, sofrimento, desestrutura a vida e 0 futuro e gera violência; a atenção ao adolescente vítima de violência: limites e avanços de uma política em construção. O sachados apontam queos gestores têm direcionado suas ações para a implementação efetiva do Programa de Saúde do A dol escente com o propósito de incluir a abordagem da violência como foco de ação.

Palavras-chave Violência, Adolescente 
Introdução

A violênciarepresenta hojeuma das principaiscausas de morbimortalidade, especial mente na população jovem. É um problema que se torna mais grave em países periféricos e em desenvolvimento, como o Brasil, principalmente, se considerarmos a questão social da desigualdade e a insuficiência das políticas públicas sociais. 0 desequilíbrio nas estruturas política, econômica e social aumenta a vulnerabilidade dos países à violência, a qual se apresenta multifacetada e formalmente diferenciada na população e nos diversos espaços públicos e privados.

Cruz N eto ${ }^{1}$ conceitua violência como um estado multifacetário por suas características externas (quantitativas) einternas (qualitativas), evento que abrange todas as esferas da vida social e individual, dela participando todos, seja como vítimas ou autores. Schraiber, D'Oliveira e Couto ${ }^{2}$ acrescentam que a violência é identificada em tempos de guerra ou de suposta paz eque não há elementos suficientes para lidar com domínio tão amplo, alimentado por interconexões ainda pouco conhecidas.

O Relatório Mundial sobre Violência e Saúde, publicado em 2002, traz dados estatísticos da violência no mundo e destaca que, no ano de 2000, países de menor renda representaram $91,1 \%$ do total das mortes violentas, concentrando os homicídios. E que 77\% dos homicídios ocorrem entreos homens e sua taxa é mais que três vezes a das mulheres, sendo maior nas faixas etárias de 15-29 anos (19,4 por $100 \mathrm{mil}^{3}$.

No que cabe à violência juvenil ( 10 a 29 anos), esta foi referida pelo mesmo relatório como a mais visível das violências e também peculiar, pois osjovens são os principais agressores e vítimas. $\mathrm{E} o$ fato deter experimentado violência na infância, pertencer a gangues e ter acesso a armas, viver sob guerra prolongada eem condições deexclusão social egrande pobreza são situações que aumentam os índices dessa violência, os maiores na América Latina eÁfrica e menores entre países do Leste Europeu ${ }^{3}$.

Hoje, as violências eos acidentes, juntos, constituem a segunda causa de óbitos no quadro da mortalidade geral brasileira. Nas idades de cinco a dezenove anos, se constitui a primeira causa entre todas as mortes ocorridas nessas faixas etárias ${ }^{4}$. No município de Salvador, capital do estado da Bahia, de 1998 a 2001, 21\% das pessoas mortas violentamente eram crianças ou adolescentes até 19 anos $^{5}$.

As crianças e os adolescentes têm se destacado como vítimas da violência por seu aspecto indefeso e baixo poder de luta ${ }^{6}$. A situação de violência tem trazido prejuízos para a população em geral, especialmente para os adolescentes, pela vulnerabilidade dessa faixa etária.

A adolescência é um dos períodos em que o indi víduo mais necessita de que as suas necessidades básicas sejam supridas. A violência sofrida tem o poder de cercear o processo de crescimento e desenvolvimento deste como pessoa e produzir a aquisição de atitudes anti-sociais e a reprodução do ciclo da violência nas gerações futuras ${ }^{6}$.

Ao se fazer o levantamento da violência brasileira, pode-sefacilmente perceber que este problema social é multifacetado, perpassa pelo desrespeito aos direitos humanos, pelas desigualdades sociais, pela insuficiência das políticas públicas e pelas diferenças regionais. Por este motivo, para o enfrentamento deste problema, é necessário que sejam adotadas ações multidisciplinares e comprometimento dos envolvidos para sustentar políticas e desenvolver condutas contra a violência.

Para o desenvolvimento dessas políticas, é sobremaneira importante 0 envolvimento dos gestores e a percepção destes de que a violência é um problema que deve ser prioridade de agenda.

Algumas políticas públicas que incluem o adolescente como grupo de atenção foram sendo criadas nas últimas décadas, a exemplo do Programa deSaúde do Adolescente(PROSAD) instituído, em 1989, pelo M inistério da Saúde. Para fortalecer as políticas públicas voltadas para a atenção ao adolescente, contamos, a partir de 1990, com o Estatuto da Criança e do Adolescente (ECA), o qual estabelece a criança e o adolescente como prioridade absolutae consolida alguns direitos constitucionais, dentreeles, 0 direito à saúde 7 . Em 1991, foi lançado, pela Associação Brasileira de Enfermagem, em parceria com o M inistério da Saúde, o Projeto Acolher. Neste mesmo ano, o M inistério da Saúde lança o Programa dos Agentes Comunitários de Saúde (PACS) e, em 1994, surge o Programa de Saúde da Família (PSF). No entanto, outras políticas públicas podem ser sustentadas pela ou com a ajuda das Secretarias de Saúde, como a Política Nacional de Redução deM orbimortalidade por Acidentes eV iolências e a Política de Redução de M orbimortalidade por Acidentes de Trânsito, dentre outras.

Com base nas responsabilidades dos municípios quanto à atenção aos seus munícipes, destacamos 0 adolescente como grupo prioritário destas ações. Considerando as condições sociais a que os jovens brasileiros estão expostos, a situação da violência que conforma a realidade de muitos adolescentes e destacando o setor saúde como 0 desaguadouro das conseqüências da violência, esta repercutindo negativamenteno desenvolvimento do 
adolescente, e os gestores de saúde enquanto atores sociais viabilizadores das políticas de atenção, apresentamos nosso interesse sobre a participação dos gestores municipais de saúde no desenvolvimento de políticas de atenção ao adolescente vítima de violência.

Devido à amplitudedo tema violência edo interesse em contribuir, de al guma forma, para discorrer sobre o problema, apresentamos como objetivo geral deste estudo: analisar a participação dos gestores municipais de saúde na aten ção ao adolescente vítima de violência no município de Itabuna, Bahia. E como objetivos específicos: identificar as percepções dos gestores municipais de saúdeacerca da violência e suas repercussões na adolescência; identificar as políticas públicas de atenção ao adolescente implantadas no sistema municipal de saúde de Itabuna, Bahia, focalizando a violência; descrever as ações desenvolvidas pel os gestores municipais de saúde para a conformação e efetivação das políticas de atenção ao adolescente vítima de violência.

\section{M étodos}

Considerando os objetivos deste estudo, optamos por adotar uma abordagem qualitativa porque, segundo $\mathrm{M}$ inayo $^{8}$, nos permite compreender a realidade concreta, os fenômenos e os processos sociais, tornando-se adequada para os estudos das práticas de saúde e das relações que se estabelecem entre sujeitos no exercício destas práticas.

Selecionamos o município de Itabuna, Bahia, por este encontrar-se há mais de um ano de Gestão Plena do Sistema Municipal de Saúde e ter uma população de 203.815 habitantes, sendo que 46.434 estão na faixa etária de 10 a 19 anos, ou seja, 22,8\% da população estão na fase da adolescência ${ }^{9}$. A rede pública de saúde em Itabuna dispõe de catorze unidades de saúde da família (USF), dez unidades básicas de saúde (UBS) e nove centros de referência. Itabuna tem $75 \%$ de cobertura pelo PACS e PSF ${ }^{10}$.

Participaram deste estudo os atores que desenvolvem, direta ou indiretamente, as atividades de gestão do sistema de saúde de I tabuna. Os entrevistados são identificados por numeração (p.ex., $E 1, E 2 \ldots)$.

U tilizamos como técnica de coleta de dados a entrevista semi-estruturada e a análise documental, as quais foram aplicadas por permitirem a expressão e a interpretação do objeto através dos depoimentos e dos registros.

Para realizarmos a análise de conteúdo, orientamo-nos pelas três etapas básicas assinaladas por
Bardin, quais sejam: a pré-análise; a descrição analítica ea interpretação inferencial ${ }^{11}$.

A proposta deste estudo foi encaminhada para - Comitê de Ética em Pesquisa da Universidade Estadual de Feira de Santana (CEP-UEFS), sob protocolo n 010/2006, em 14 de março de 2006, e obteve aprovação em 2 de maio de 2006.

Ressaltamos o cumprimento das normas legais exigidas para a realização de estudos que envolvam seres humanos.

\section{Resultados ediscussão}

Organizamos os resultados e discussão dos achados, orientadas pel as categorias analíticas queemergiram deste estudo, as quais estão representadas nos três subcapítulos que seguem.

A violência enquanto qualquer forma de agressão física, moral, psíquica, social, omissão e desrespeito aos direitos humanos

Percebemos que o entendimento que os gestores de saúde apresentam acerca da violência não está restrito a uma área de conhecimento apenas. Os gestores percebem a violência como fenômeno referente ao ser humano, cuja manifestação se dá mediante as relações sociais (Estado, sistema e sociedade), quando estas são marcadas por atos de agressão de qualquer forma, omissões e situações de desrespeito aos direitos do homem, como bem mostra esta fala de um dos nossos entrevistados: Pra mim todas essas pessoas todas são vítimas da sociedade, são vítimas do sistema (E12).

A violência, enquanto fenômeno queocorreem todas as esferas da vida social, tem suas raízes no modo como a sociedade se estrutura e se relaciona. Segundo Santana e Souza ${ }^{6}$, a violência é construída socialmente e ganha variadas formas de expressão por estar relacionada às transformações sociais, políticas, econômicas e culturais e, também, às concepções de cidadania e de homem enquanto sujeito.

Buscamos o entendimento dos gestores da saúde municipal deltabuna, por esse município baiano se destacar quanto ao número de mortes por violência. Noronha e Daltro ${ }^{12}$ desenvolveram um estudo que pretendeu analisar os diferenciais por gênero de mortes violentas e outras agressões ocorridas na Bahia. Este estudo mostrou que a violência tem destaque no estado da Bahia, ressaltandose que, no interior desse estado, destacam-se as cidades de I tabuna, Feira de Santana e Vitória da Conquista. 
A violência podeser entendida por alguns como uso da força contra ou sobre alguém. Para Zenaide ${ }^{13}$, a violência traduz-se no uso da coerção ou força, um dispositivo de poder sobre o outro, com produção de danos. M ichaud ${ }^{14}$ declara que a idéia de força constitui o núcleo central da violência e contribui para fazêla designar comportamentose ações físicas.

O Relatório Mundial sobre Violência e Saúde faz referência ao uso da força e do poder quando define a violência como o uso intencional da força física ou do poder, real ou em ameaça, contra si próprio, contra outra pessoa ou contra um grupo ou uma comunidade, queresulte ou tenha a possibilidade de resultar em lesão, morte, dano psicológico, deficiência de desenvolvimento ou privação ${ }^{3}$. Um dos nossos entrevistados esboça o que compreende por violência: Violência é qualquer, assim, qualquer ato de agressão de um indivíduo para um indivíduo (E11).

O M inistério da Saúde, através da adoção de uma Política de Redução deM orbimortalidadepor Acidentes e Violências, define como violência "o evento representado por ações ou omissões realizadas por indivíduos ou grupos, classes, nações, que ocasionam danos físicos, emocionais, morais e espirituais a si próprio ou aos outros" ${ }^{15}$, um conceito que não passou despercebido a um dos depoentes, queo referecom absoluta clareza: Q ualquer ato ou ação ou omissão que causa dano a pessoa, ao ser humano, a qualquer ser, de modo quetire dela o poder de ação, o poder de defesa no sentido de que ela venha a sofrer conseqüências patrimoniais, financeiras, psicológicas, sociais, educacionais (E12).

A omissão também pode estar camuflada no desconhecimento. Segundo Silva e Santana ${ }^{16}$, ambas situações se constituem terreno fértil para a manutenção dos episódios de violência, além de expor os vitimizados a mais um tipo de violência, a negligência, seja ela profissional, institucional ou por parte da sociedade.

A violência faz mal à saúde e é, especialmente, prejudicial na adolescência, quando o indivíduo encontra-se em plena fase de desenvolvimento. Portanto, diante da complexidade do fenômeno e da dimensão dessa problemática, impõe-se o desenvolvimento deações multissetoriais emultiprofissionais, bem como a participação dos gestorese a vontade política para a implantação de políticas de atenção.

O Brasil, com forma de governo considerado democrático, porém com processo neoliberal em expansão, tem a violência como um grave problema de saúde pública. Se analisarmos a qualidade de vida dos brasileiros e relacionarmos com a distri- buição de renda e as condições de pobreza, veremos que a forma de violência expressa por Mertens, citado por Gomes"17, a "violência silenciosa", está presente de forma bastante velada. Esta é produto da situação de exploração e desigual distribuição de renda que configuram as relações entre 0 Estado e a sociedade. 0 envolvimento dessas duas instituições, Estado e sociedade, foi, assim, referido pelos sujeitos: U m conjunto de agressões, de irregularidades que atingem não só 0 indivíduo quanto 0 Estado, a ordem pública (E7).

Considerando a violência como contrária ao direito e à justiça, entendemos que o Estado, enquanto poder público representado pelos gestores, pode, dealgum modo, intervir nessa realidade, com vistas a reduzir as desigualdades mediante o provimento de políticas públicas sociaisque ensejem meIhorias para a qualidade de vida das populações.

“Toda ação ou omissão que viola os direitos garantidos pela constituição e pelas leis é uma violência" diz González ${ }^{18}$. Os adolescentes, enquanto cidadãos, devem gozar dos direitos sociais queconfiguram os direitos aos padrões de vida que prevalecem na sociedade.

O Estatuto da Criança e do Adolescente(ECA) estabelece os direitos específicos dos adolescentes como cidadãos no interior das áreas abordadas pela Constituição, como saúde, educação, profissionalização. Além disso, o Estatuto apresenta dispositivos legais para a garantia e o zelo dos direitos dos adolescentes.

Os maus-tratos (referem-se à descrição dos danos causados pelo abuso, aos atos e suas conseqüências) cometidos contra a criança e 0 adolescente podem ser praticados pela omissão, pela supressão ou transgressão dos seus direitos definidos por convenções legais ou normas culturais ${ }^{19}$. É o que confirma o seguinte depoimento sobre a violência e os maus-tratos: É infringir os direitos humanos, é você ir de encontro ao que é de direito, ao que 0 estatuto determina. Então, você não ter direito à saúde, não ter direito à educação, não ter direito à alimentação, moradia, pra mim isso já é uma forma de violência (E6).

Os serviços públicos de saúde devem incluir o acesso e acompanhamento de profissionais da área. Sua inexistência ou negação pode ser combatida através de ações previstas no ECA. Este estatuto, na altura do artigo 245 , refere que a não comunicação do profissional, inclusive o de saúde à autoridade competente, de casos quetenha conhecimento, envolvendo suspeita ou confirmação de maus-tratos contra crianças ou adolescentes, incorre em multa detrês a vintesalários dereferência ou o dobro, em caso de reincidência ${ }^{20}$. 
0 depoimento, a seguir, confirma que os gestores estão cientes de que a violência pode representar uma omissão ou um ato, como a falta de atendimento ou o mau atendimento pelo profissional de saúde, o que representa desrespeito aos direitos humanos: Quando a gente passa a não atender bem essecliente, atéas formas mesmo deagressão física, dentro da comunidade. 0 atendimento do profissional, a depender da forma que for colocada a ele, a resposta que a gente não dá (E1).

A violência é determinada por fatores estruturais (desigualdades sociais, diferenças regionais, desigual concentração de riqueza), por fatores culturais e fatores ético-políticos (crise dos valores democráticos, baixo exercício da cidadania, falta de vontade política para apurar a responsabilidade penal de agressões, falta de controle do Estado por parte da sociedade civil) ${ }^{13}$.

Apesar das garantias democráticas acerca da universalidade dos direitos humanos expressas na Constituição de 1988 e no ECA, políticas públicas descomprometidas têm tornado o Estado um dos principais responsáveis pela violência estrutural.

A violência repercute psicologicamente na adolescência, causa dor, sofrimento, desestrutura a vida e o futuro

e gera violência

Os gestores municipais, enquanto formuladores e, também, executores de políticas públicas, constatam que a fase da adolescência, quando marcada por episódios de violência, pode transcorrer com perturbações psicológicas e dificuldades nas relações as quais desestrutura a vida e interfere na forma de ver e viver o mundo. Pode, inclusive, desenvolver comportamentos violentos. É sobre essas repercussões na vida do adolescente que trataremos nesta categoria.

Segundo Pereira, Santana e Ferriani ${ }^{21}$, o processo de adolescer implica características que, por si sós, conferem a esta fase determinado grau de vulnerabilidade, o que exige atenção e cuidados especiais. A violência, queacomete essa fase, interfere no crescimento pessoal do adolescente e pode proporcionar a aquisição de valores e comportamentos anti-sociais.

A violência se inscreve nas relações sociais, re percutindo nas dimensões somática, emocional, intelectual esocial do ser humano. N este estudo, os gestores de saúde se colocaram, com maior ênfase, quanto às dimensões psicológica e emocional.

A violência material (saúde, alimentação, habitação) e a intelectual (educação, lazer) junto à desagregação familiar tem influência importante no desenvolvimento emocional da criança e do adolescente, o que vai acompanhar a trajetória deste ser humano, prejudicando a sua realização como indivíduo ${ }^{18}$. É o que mostra este depoimento: Violência gera violência, quem tem no seu lar, na sua formação convivido com cenas de violência, parte do seu cotidiano vai se incorporar como valores, vai ser natural e, mais tarde, essas pessoas voltarão a viver as mesmas práticas que elas conviveram durante a sua formação (E5).

A violência compromete o crescimento eo desenvolvimento do adolescentee deixa seqüelas duradouras. 0 meio social transmite ao adolescente o modelo de vida que influencia na expressão do seu comportamento presente e futuro. Isto porque a vida cotidiana, o dia-a-dia, o convívio social e intrafamiliar refletem no modo de ver e viver no mundo e na forma de encarar a vida. É o que expressam estes entrevistados: Eu acho que pra ninguém, mais do que pra criança e pro adolescente, a violência pode trazer tanta repercussão. Tipo traumas mesmo, que vão prejudicar a vida dele futura, de se tornar, até, uma pessoa violenta em decorrência da pessoa sofrida que é. Caso ele não tenha um apoio psicológico da família, eu acho que isso pode repercutir na vida dele futura, na formação dele, de jovem, adulto e ele pode trazer consigo essa violência da qual ele sofreu (E13).

A sociedade, incluindo os diversos espaços nos quais 0 adolescente interage, tem papel estruturador ou desestruturador. Quando a sociedade está em estado de confusão, o adolescente sente-se menos seguro emais perturbado. Pode, então, sentir-secompelido a praticar atos de violência contra os outros ou contra si mesmo 22 .

Portanto, chamamos a atenção para o papel desestruturador que o ambiente "rua" exerce sobre a criança e 0 adolescente, pois, neste espaço, todos, inclusi veos adolescentes, estão expostos aos diversos riscos e se tornam vítimas fáceis. Outros ambientes ou espaços também podem interferir naforma deviver do adolescente. Instituições, como presídios, escolas e abrigos, têm se caracterizado pelo seu caráter violento, devido às normas, regras e funcionamento destas.

Segundo Silva e Guerese ${ }^{23}$, a noção de prevenção encontra-se ainda muito dissociada das propostas deatuação das instituições brasileiras, dado que em muitas destas persistem problemas que, se não gerais, constituem focos de relevante preocupação na perspectiva dos direitos humanos e saúde destes adolescentes: instituições ainda sob uma concepção repressiva, fal ta de capacitação dos trabalhadores, deficiente assistência médica e odontológica, precária escolarização. 
Assim, muitos dos danos produzidos nestas instituições podem estar invisíveis, por colocar outros referenciais na vida das pessoas, que aí são instaladas, e que têm seus familiares substituídos por funcionários ou policiais, o que potencialmente prejudica o desenvolvimento de relações sociais e humanas.

Para Agudelo ${ }^{24}$, a violência não se reduz a um dano ou a um momento. Ela é um processo orientado para fins determinados a partir de diferentes causas, formas variadas, produzindo danos, alterações e conseqüências imediatas ou tardias.

Portanto, os cuidadores, assim como os gestores, devem estar cientes que a violência compromete 0 crescimento e o desenvolvimento dos adolescentes em seus múltiplos aspectos, constituindo-se, assim, em uma demanda de saúde pública. Se considerarmos que os eventos violentos podem ser repetitivos, duradouros e crônicos, constatare mos a necessidade de implantarmos serviços e políticas de atenção urgentes a essa clientela que levará consigo, além das conseqüências somáticas, as psicológicas e sociais.

Contudo, a implantação e sustentação desses serviços e políticas somente será possível sehouver vontade política, capacidade de articulação interinstitucional dos setores e elaboração conjunta de proposta de trabalho integrado. E, ainda, os gestores devem compreender e garantir a base logística do processo, além de estabelecer mecanismos de acompanhamento e avaliação.

Atenção ao adolescente vítima de violência: limites e avanços

de uma política em construção

N esta categoria, tratamos de descrever e analisar as políticas de atenção ao adolescenteem situação deviolência, desenvolvidas pelo setor saúde no município de Itabuna. Entretanto, iniciativas de outros setores também foram referidas pelos entrevistados, dado que al gumas delas desenvolvemse em articulação com o setor saúde.

As políticas de atenção podem apresentar-se enquanto proposta ou estratégia de intervenção cujas ações contemplem al guma das etapas de atenção, as quais são apresentadas por Assis e Constantino ${ }^{25}$ por três denominações: prevenção primária, prevenção secundária e prevenção terciária. $\mathrm{Na}$ primeira, a atuação deve está voltada para os fatores contribuintes e os agentes da violência, embora as autoras afirmem que esta tem sido a estratégia menos utilizada. Q uanto à prevenção secundária, refere-se a respostas mais imediatas à violência, enfocando a capacidade de diagnóstico, trata- mento precoce e limitação da invalidez; quanto à terciária, diz respeito às respostas em longo prazo, destinadas ao processo de reabilitação das vítimas.

Sobre as etapas de atenção, vale salientar que estas podem ser desenvolvidas por setores diversos, como o jurídico, a educação, a segurança, a assistência social e inclusive pelo setor da saúde.

O setor da saúde constitui o espaço para onde confluem todos os "corolários" da violência, pela pressão que exercem suas vítimas sobre os serviços deurgência, deatenção especial izada, de reabilitação física, psicológica e de assistência social2 ${ }^{26}$. Esse fato aponta para a necessidade de o poder público assumir essa situação como um problema de saúde pública e capacitar os profissionais para o exercício dessa função, bem como lutar por uma melhor política de financiamento epor maior aporte de recursos tecnológicos.

A negligência dos formuladores de políticas, quanto à elaboração de propostas de atenção aos vitimizados e combate à violência com recursos suficientes e garantia do atendimento de referência, potencializa o não encaminhamento, bem como a não notificação dos casos.

Silva e Silva ${ }^{27}$ acrescentam que a prestação de uma assistência efetiva que contemple os aspectos individual, institucional e social, dar-se-á, sobretudo, mediante o estabelecimento de sistemas de referência entre o setor saúde e os outros setores assistenciais.

Osgestores têm identificado algunsentraves para a oferta das ações e serviços, como: 0 despreparo na formação dos profissionais de saúde para a abordagem ao vitimizado, a precariedade de recursos, a ineficiência dos encaminhamentos e a falta de articulação entre os diversos setores, inclusive o jurídico. É o que mostram os seguintes depoimentos:

Os próprios profissionais que trabalham na rede não estão ainda sensibilizados, não sabem como acoIher (E11).

Aqui não tem ainda uma normatização pra a gente saber pra ondeéque vai, o queéquefaz, encaminhamento, referência não tem (E4).

A gente tem dificuldade com a Promotoria Pública, com a questão do Juizado de M enor. Esse respaldo a gente está tentando agora, conseguindo agora depois do Projeto Sentinela (E 14).

Diante das inúmeras repercussões da violência sobre os adolescentes, é fundamental promover 0 compromisso dos gestores com o intuito de implantar e implementar políticas de combate e enfrentamento da violência. No caso de Itabuna, os gestores da saúde são sensíveis à questão das repercussões da violência e são conscientes da sua responsabilidadee da necessidade de articulação entre 
os diversos setores pela amplitude e extensão que a violência toma. No entanto, referem como uma das maiores dificuldades a insuficiência dos recursos financeiros; vejamos o seguinte depoimento: Aqui em Itabuna, quetem uma população habitacional de 203.815 habilitantes, segundo o IBGE, que, na verdade, ultrapassa os 250.000 fixo, tem uma população flutuante pactuada que consta em torno de um miIhão e sei scentos a dois milhões enovecentos que vem parar em Itabuna. Então, você imagina o tamanho da responsabilidade de uma secretaria que detém metade do orçamento do município pra resolver essas ações. Não é brincadeira! (E12).

O problema clássico da escassez ou inexistência dos recursos para financiamento das políticas sociais, somado às históricas dificuldades como a centralização política e administrativa, a desarticulação de programas e ações, o desvio de recursos, entre outras, revela a complexidade da realidade brasileira ${ }^{28}$.

É crescente o número de crianças e adolescentes que chegam à rede pública de saúdeeàs clínicas particularescomo vítimas demaus- tratos, deabuso físico, sexual, psicológico, de negligência ou de abandono. Por isso, a equipe de saúde deve estar capacitada, sensibilizada para o tema, adquirindo incessantemente conhecimentos erefletindo sobre os mitos e preconceitos para que 0 atendimento seja prestado sem a presença de juízo de valor. Portanto, o acompanhamento deverá ocorrer de formaintegrada com as equipes do PACS/PSF ea equipe dos Centros de Referência ${ }^{27}$.

A estratégia de saúde da família criada pelo M inistério da Saúde constitui-se em uma política de atenção que busca a promoção da saúde e a prevenção de agravos, assim como a prestação da assistência no nível primário. Os profissionais que atuam na equipe ocupam uma posição favorável na detecção dos possíveis fatores de risco por atuarem em áreas adscritas. Entretanto, não se percebe uma atuação efetiva desses profissionais pelo despreparo que apresentam e pela indefinição das atribuições destes quanto à problemática da violência.

Os indicadores do sistema de informação da atenção básica (SIAB) de Itabuna, Bahia apontam $42 \%$ da população coberta pelo PACS e $33 \%$ coberta pelo PSF (zona urbana e rural) ${ }^{10}$.

Dentre as muitas políticas de atenção voltadas para o adolescente e que são desenvolvidas no âmbito municipal, trazemos também o PROSAD, o qual já foi implantado no município de Itabuna, todavia, sem implementação nas unidades, estando sendo desenvolvidas, ainda, ações individualizadas pelo atendimento médico ou de enfermagem e ações educativas.
O Programa de Saúde do Adolescente tem por objetivo a promoção da saúde, mediante o desenvolvimento de práticas educativas, identificação de grupos de risco, diagnóstico precoce dos agravos, tratamento e recuperação. Na realidade, de muitos municípios brasileiros, inclusive baianos, observa-se 0 interesse de alguns gestores em querer implantar o programa.

O Relatório de Gestão 2005 do município de I tabuna revela o compromisso com a rede básica de saúde e destaca as áreas de saúde que tiveram avanço, a exemplo da área de Saúdedo Adolescente, que, segundo o referido documento, teve implantado eefetivado neste ano o Programa deSaúde do Adolescente ${ }^{10}$.

Portanto, para os gestores, ainda não se nota o programa funcionando efetivamente. Entretanto, na busca pela operacionalização efetiva do PRO$\mathrm{SAD}$, um noticiário jornalístico, datado de agosto de 2006, informou que os técnicos e gestores da Secretaria M unicipal de Saúde querem referenciar - PROSAD para os demais 104 municípios pactuados com o Sistema Ú nico de Saúde (SUS) de I tabuna. Informou, também, sobre o curso de capacitação promovido neste mês pela Secretaria de Saúde do Estado da Bahia (SESAB) para os 21 municípios gerenciados pela 7a DIRES, dentre eles I tabuna, que teve duração de cinco dias, em que foram abordados pela equipe do CRADIS temas como, Violência na Adolescência, Sexualidade, Contracepção, Doenças Sexualmente Transmissíveis e aids (DST/aids).

Para reduzir a incidência da violência, acreditase que o investimento do setor público e o direcionamento das ações com base na promoção de saúdeseja a estratégia mais coerente. Portanto, iniciativas têm sido implantadas pelos municípios nesse intuito. Dentre elas, tem-se no município em estudo, algumas já em operacionalização e outras implantadas (do próprio setor saúde e também de outros setores), porém, ainda não executadas. Quanto à conquista destas políticas em execução, foi resultado da participação e do empenho dos gestores que apontam como maior dificuldade a restrição dos recursos financeiros, mas que tem como elemento facilitador a articulação com outros setores, a exemplo do setor de desenvolvimento social.

U ma política de atenção que está sendo adotada de forma expansiva nos municípios é o Centro de Aten ção Psicossocial (CAPS). OsCAPS são unidades de saúde locais/regionalizadas que oferecem atendimento de cuidados intermediários entre 0 regime ambulatorial e a internação hospital ar, por equipe multiprofissional. $\mathrm{Na}$ realidade local estu- 
dada, como resultado da participação e iniciativa dos gestores, têm implantadas duas modalidades desse serviço, o CAPS álcool edrogas (CAPS ad) e o CAPS da infância e adolescência (CAPS ia).

Outras políticas implantadas por outros setores também foram citadas pelos gestores de saúde que participaram deste estudo, as quais vêm sendo desenvolvidas de forma articulada e intersetorial, como exemplo, o Projeto Sentinela, queseconstitui num conjunto de ações sociais especializadas e multiprofissionais dirigidas a vítimas da violência sexual que faz parte do Plano Nacional de Enfrentamento à Violência Sexual Contra Crianças eAdolescentes do governo federal, projeto este que tem tido 0 envolvimento do setor saúde e tem sido 0 eixo estruturador do serviço de atenção ao adolescente e de suporte ao profissional da saúde. Vejamos o seguinte depoimento: A gente tem, mais ou menos, dez meses de projeto implantado no município, então implementado em quatro unidades, mas quea gentevêqueatéo final do ano todas asunidades já estarão fazendo porqueo projeto Sentinela está fortalecido no município (E2).

Outras ações vêm sendo desenvolvidas em I tabuna. A rede municipal de atenção básica de saúde, através de seus profissionais, tem desenvolvido sessões educativas em grupo de adolescentes.

Uma outra iniciativa citada por muitos entrevistados foi o Projeto "Adolescentes em Ação", elaborado por uma enfermeira que atua em uma das equipes de saúde da família de Itabuna. 0 projeto busca, dentre outros objetivos, oferecer aos adolescentes assistência integral, bem como propiciar a implantação do PROSAD, diminuir o índice de gravidez, DSTs e ai ds, violência intra e extra familiar edependência química, além de resgatar o princípio da cidadania. Segundo a autora, pela abrangência da proposta de intervenção, esta acabou tomando a dimensão de projeto, por parte do de partamento de atenção básica. No entanto, apesar do interesse, por parte da gestão da atenção básica, foram apontadas, pela entrevistada, algumas dificuldades que se têm enfrentado para a implantação do projeto, inclusive a falta de suporte para a estruturação deste serviço.

Por outro lado, a iniciativa do gestor municipal e a sua visão ampliada, que permitiu conferir a uma proposta a dimensão de projeto, permitemnos perceber a influência positiva eo estímulo para fazer com que este projeto se torne uma ação.

Outros projetos têm sido executados por parte do Centro de Referência de DST aids da Secretaria M unicipal deSaúde, a exemplo: N óstemosum projeto aqui chamado "Intervenção de prevenção" que trabalha, sobretudo, com foco nos estudantes adoles- centes. Estamos preocupados com a questão da infecção DST, HIV, aids. O utro proj eto chamado "Ronda noturna" que a gente trabalha com a questão mais do submundo, embora o projeto seja dirigido para os profissionais do sexo, caminhoneiro e comunidade gay, a gente também não deixa de atender a menino derua (E7).

Segundo o entrevistado (E7), o Centro de Referência de DST aids tem o adolescente como público-alvo, o qual ao procurar o serviço éatendido evisto inicialmente como vítima. Imediatamenteé assistido no sentido de recuperá-lo psicologicamenteefisicamente.

Não obstante essas iniciativas, não foram citadas nas entrevistas, tampouco observadas nos documentos, a implantação e execução da Política de Redução da M orbimortalidade por Acidentes e Violências. Entretanto, as políticas, ações e projetos aqui apresentados declaram a intenção, o esforço e a iniciativa dos gestores para garantir, dentro do possível, a prevenção, a atenção e a reabilitação dos adolescentes vítimas de violência.

Portanto, embora não tenhamos esgotado a discussão sobre as políticas de atenção ao adolescente desenvolvidas no município del tabuna, concluímos que os gestores municipais de saúde, que foram incluídos neste estudo, participam de forma a contribuírem direta ou indiretamente para a implantação destas políticas.

\section{Consideraçõesfinais}

Este estudo buscou analisar a participação dos gestores no desenvolvimento de políticas de atenção ao adolescentevítima de violência no município de I tabuna, Bahia, frente à magnitude e impacto desse fenômeno apontado como um grave problema de saúde pública.

Os resultados deste estudo permitem sinalizar a responsabilidadeque os gestores devem ter quanto à elaboração e sustentação das políticas. Contudo, a forma de pensar dos gestores acerca deste fenômeno traduz práticas e ações que se concretizarão em propostas políticas capazes de produzir mudanças na real situação da violência local.

0 estudo induz a pensar possíveis propostas de ação pelos gestoreseseressalta por revelar a necessidade de se elaborar novas investigações sobre as políticas de atenção queenfocam a violência, uma vez que se deteve em descrever as experiências de implantação eimplementação eidentificando os entravese os limites deoperacional ização, ou então sugerindo estratégias de viabilização que levem à expansão do atendimento nas demais unidades e municípios. 


\section{Colaboradores}

M KB Souza trabalhou na pesquisa, metodologia, resultados e discussão; JSS Santana trabalhou na revisão crítica e redação final.

\section{Referências}

1. Cruz Neto O. Corpos e sonhos destruídos: relações entre violência, pobreza e exclusão social [tese]. Rio de Janeiro: Escola Nacional de Saúde Pública, Fundação Oswaldo Cruz; 1995.

2. Schraiber LB, D'Oliveira AFPL, Couto $M T$. Violência e Saúde: estudos científicos recentes. Rev. Saúde Pública 2006; 40(N Esp):112-120.

3. Krug EG, Dahlberg LL, M ercy JA, Zwi AB, Lozano R, editors. World Report on violence and health. Genebra: World Health Organization; 2002.

4. Brasil. Ministério da Saúde. Secretaria de Vigilância em Saúde. Departamento de Análise de Situação em Saúde. Saúde Brasil 2005: uma análise da situação de saúde no Brasil. Brasília: M inistério da Saúde; 2005.

5. M ortes de residentes em Salvador de 1998 a 2001. In: Fórum Comunitário de Combate à Violência, 2. 0 rastro da violência em Salvador. Salvador: Fórum Comunitário de Combateà Violência/ U N ESCO/U FBA; 2002.

6. Santana JSS, Souza SL. Violência em situação de rua. In: Costa COM, Souza RP, organizadores. Adolescência: aspectos clínicos e psicossociais. Porto Alegre: Artmed; 2002.

7. Brasil. Ministério da Saúde. Conselho Nacional dos Direitos da Criança e do Adolescente. Diretrizes $\mathrm{Na}$ cionais para a Política de A tenção Integral à Infância e à Adolescência - 2001-2005. Brasília: Ministério da Saúde; 2001.

8. M inayo MCS, Assis SG, Souza ER, Njaine K, Deslandes SF, Silva CM FP. Fala galera: juventude, violência e cidadania no Rio de Janeiro. Rio de Janeiro: Garamond; 1999.

9. Brasil. M inistério da Saúde. Dados populacionais. Datasus. [site na Internet]. 2005 [acessado 2005 ago 19]. Disponível em: http://tabnet.datasus.gov.br

10. Bahia. Secretaria M unicipal de Saúde de Itabuna. Departamento de Atenção Básica. Relatório de Gestão 2005. Itabuna: Secretaria Municipal de Saúde; 2006.

11. Triviños ANS. Introdução à pesquisa qualitativa em ciências sociais: a pesquisa qualitativa em educação. São Paulo: Atlas; 1987.

12. Noronha CV, Daltro ME. A violência masculina é dirigida para Eva ou Maria? Cad Saúde Pública 1991; $7(2): 215-231$.

13. Zenaide $M N T$. Fundamentos teóricos sobre a violência [site na Internet]. 2005 [acessado 2005 out 31]. Disponível em: www.dhnet.org.br/direitosmilitantes/ nazarezenaide/nazare_violencia.htlm

14. Michaud Y. A violência. São Paulo: Ática; 1989.

15. Brasil. Ministério da Saúde. Portaria no 737 de 16 de maio de 2001. Política Nacional de Redução da Morbimortalidade por Acidentes e Violências. Diário Oficial da União 2001; 18 mai.
16. Silva EC, Santana JSS. Informações sobre maus tratos na infância e adolescência entre enfermeiros(as) de um hospital público de Feira de Santana - Bahia. Feira de Santana; 2001. [M imeo].

17. Mertens P. Violência institucional, violência democrática y represión. In: Gomes R. A violência em questão: referenciais para um debate em saúde pública. Rev Latino-am Enfermagem 1997; 5(2):93-100.

18. González RS. Saiba como dizer não à violência: orientações para a defesa dos direitos da criança e do adolescente. Porto Alegre: Movimento Nacional de Meninos e M eninas de Rua; 1995.

19. Gomes R, Junqueira M FP da S, Silva CO, Junger WL. A abordagem dos maus-tratos contra a criança e 0 adolescente em uma unidade pública de saúde. Cien Saude Colet 2002; 7(2): 275-283.

20. Brasil. Lei 8.069/90 de 13 de julho de 1990. Dispõe sobre o Estatuto da Criança e do Adolescente e dá outras providências. Diário Oficial da U nião 1990; 13 jul.

21. Pereira SM, Santana JSS, Ferriani M GC. Violência rima com adolescência? In: Ramos FRS, organizador.Adolescer: compreender, atuar, acolher: Projeto Acolher. Brasília: ABEn; 2001.

22. Lewis M, Wolkmar F. Adolescência. In: Lewis M, WoIkmar F. Aspectos clínicos do desenvolvimento na infância e na adolescência. 3ạ ed. Porto Alegre: Artes M édicas; 1993. p. 219-257.

23. Silva E, Gueresi S. Adolescentes em conflito com a lei: situação do atendimento institucional no Brasil [texto para discussão no 979]. Brasília: I pea; 2003.

24. Agudelo SF. Violência y/o salud: elementos preliminares para pensarlas y actuar. Rio de Janeiro: Claves/ Ensp/Fiocruz; 1989. [M imeo].

25. Assis SG, Constantino P. Perspectivas de prevenção da infração juvenil masculina. Cien Saude Colet 2005; 10(1):81-90.

26. M inayo M CS, Souza ER. Violência para todos. Cad Saúde Pública 1993; 9(1):65-78.

27. Silva MCM , Silva LMP. Guia de assistência integral à saúde da criança e do adolescente em situação de violência: abordagem multidisciplinar. Recife: EDUPE; 2003.

28. Brasil. M inistério da Saúde. Programa de Saúde do Adolescente [site na Internet]. 2005 [acessado 2005 out 31]. Disponível em: http://www.saude.ba.gov.br/int_ acoes_prog.htlm

Artigo apresentado em 11/04/2007

Aprovado em 14/12/2007

Versão final apresentada em 15/01/2007 